\title{
The Valuation of Executive Stock Option Using the Integral Representation Method
}

\author{
Yi-Long Hsiao', Li-Ling Chen², Chien-Jung Ting ${ }^{3}$ \\ ${ }^{1}$ Department of Finance, National Dong Hwa University, Taiwan \\ ${ }^{2}$ Department of Food and Beverage Management, Tatung Institute of Technology, Taiwan \\ ${ }^{3}$ Department of Leisure, Recreation, and Tourism Management, Southern Taiwan University of Science and Technology, Taiwan \\ Email: hsiao@mail.ndhu.edu.tw, judychen@ms2.ttc.edu.tw, cjting@stust.edu.tw
}

How to cite this paper: Hsiao, Y.-L., Chen, L.-L. and Ting, C.-J. (2020) The Valuation of Executive Stock Option Using the Integral Representation Method. Journal of Mathematical Finance, 10, 431-447.

https://doi.org/10.4236/jmf.2020.103026

Received: May 4, 2020

Accepted: August 23, 2020

Published: August 26, 2020

Copyright $\odot 2020$ by author(s) and Scientific Research Publishing Inc. This work is licensed under the Creative Commons Attribution International License (CC BY 4.0).

http://creativecommons.org/licenses/by/4.0/

\begin{abstract}
This study derives a closed-form approximate solution for Bermudan reset executive stock options with cash dividends. The complicated payoff characteristic of this exotic option is caused by its particular stylistic features, including the reset mechanism, cash dividends, early exercises, and increasing volatilities. Using the integral representation method, a closed-form approximate solution was successfully derived. Moreover, this study discusses how specific critical factors affect executive stock option values and arrives at some interesting results by way of a numerical calibration.
\end{abstract}

\section{Keywords}

Executive Stock Option, Heat Equation, Green's Function, Reset Option, Integral Representation Method

\section{Introduction}

Executive stock options (ESOs) have recently become a popular managerial tool in corporate governance. In recent years, a large number of firms have used stock options as an auxiliary method of executive compensation and as a tool for reducing agency costs. ESOs give corporate executives and employees the right to buy corporate shares at a pre-specified exercise price. Due to their widespread use and complexity, the topic of ESO valuation is worthy of analysis. Numerous studies have developed various valuations of options ([1]-[7]). Several techniques for valuing options have been developed, including the binomial tree models ([8] [9] [10]), the certainty-equivalence method [5], portfolio analysis ([11]), and the utility-indifference approach (see [11] [12] [13]). 
Another concern in considering option valuation is the characteristic styles of ESOs. The early exercising feature of ESOs has been considered by several studies ([3] [11] [14] [15]). For example, [10] solved the early exercise problem using the binomial model framework. In addition, [3] gave a valuation for resettable European-style ESOs. Also, [7] and [16] considered asset risk in ESO pricing, finding that cash dividend payments could increase the underlying asset's volatility. These studies separately provided some closed-form or numerical solutions for executive stock options in terms of ESO's characteristic styles themselves.

Due to the fact that cash dividends from the underlying assets of ESOs can be paid before the time of maturity, ESO holders will consider the possibility of early exercise. Specifically, in the case of long-term ESOs, holders face several early exercise decisions until the expiration of the contract. Consequently, the holders have a series of several exercisable opportunities to close the contract. In this paper, we examine a potential concern about the valuation of an option life closed series because when it is in a general executive stock option contract, it is allowed to be exercised early. Obviously, this option embodies the characteristics of a Bermudan-type option. For these reasons, we attempt to derive the exact valuation of Bermudan executive stock options with cash dividends. We consider the possibility of early exercise to conform with the real phenomenon, which sees firms usually pay cash dividends to shareholders. Moreover, adverse stock performances in the economic environment do not always benefit executives. A mechanism to reset the strike price is designed as a form of compensation for those executives facing a market condition with lower stock performance. As a result, this paper also focuses on more complex problems germane to this type of stock option, which reflect both corporate and executive realities. To address these problems stemming from ESO contracts being resettable, having the possibility of early exercise, allowing for the payout of cash dividends, and being subject to increasing stock volatility, we provide an exact solution for such options.

A comparison of our work to previous studies of executive stock options suggests that our study makes an advanced contribution to the literature. Previous studies individually analyzed ESO stylistic facts at their valuation models based on various considerations of early exercise, cash dividends, underlying asset volatility, and resettable contracts; however, the current study integrates these stylistic facts into our pricing models and provides an exact solution for this complicated problem through Green's function and the recursive integral method. Compared to several traditional methods such as the binomial tree model, risk neutral measures, portfolio analysis, and utility indifferences, the recursive integral method proves to be a more flexible and feasible technique by which to price derivatives. That is, the current study aims to find the valuation for Bermudan resetting options with cash dividends and increasing volatilities. We apply the results of our research to the valuation of ESOs with reset rights, and take some numerical examples to discuss the features of ESOs under different parameters. In the best of our knowledge, there are no studies that simultaneously 
consider the numerous and complicated above-mentioned conditions in the ESO pricing problem.

We arrange the remaining sections of this paper as follows: Section 2 discusses related literature on executive stock options. Section 3 further develops the valuation model for the ESOs. Section 4 contains detailed interpretations of the decision factors with a simple numerical calibration. Finally, we draw some conclusions.

\section{Related Literature}

Derivatives have gradually become more and more popular in financial markets and in practical business contracts since [17] derived the valuation formula of plain vanilla European options. Many firms have even adopted derivative tools as a payment mechanism for executive compensation in recent years. The ESO is a useful tool, acting as a payment mechanism in addition to regular salary payments. Executive stock options have several stylistic features, in practice. For example, the resettable strike prices of ESOs cause valuation difficulties. The cash dividends from the underlying stock also further increase the demand for price solution techniques. Moreover, issuing ESOs can itself increase underlying asset volatilities, so as to cause difficulty in terms of valuation.

There are numerous studies that have tried to price options which include the stylistic features of ESOs. For example, in considering the pricing of reset options, [18] and [19] studied a reset warrant of the S\&P 500 index and derived a closed solution in a single period framework. [20] further derived a closed solution of reset options with discrete multiple periods in risk-neutral economics. [21] extended the work of [20] and used multiple normal distribution functions to present the valuation of reset options with multiple reset periods. Turning to executive stock options, [3] first considered the resetting characteristics. They found that the resetting feature had only a small influence on the option valuation and had a strongly negative correlation with corporate performance. Considering the American style, the resetting feature, and the trading restrictions on executives, [6] provided an analytical and flexible method for valuing executive stock options. They could obtain a near-explicit solution on the exercising strategies. [22] derived a new framework to value employee stock options (ESOs) with multi-exercises, and they also modeled the risk of ESO holders. [23] priced executive stock option under GARCH models. [24] considered a GARCH process to describe the variance of the stock and employment shocks by a doubly stochastic Poisson process. [25] developed a model to price executive stock options (ESOs) considering two sources of early exercise via a Monte Carlo simulation with about 4000 US executive data. [26] produced an analytical Reset ESO valuation with resetting of vesting period, exercise window, reset level and maturity.

Another line of inquiry into executive stock options has discussed ESO issuance and how it influences stock risk. An empirical study conducted by [16] 
indicated that the stock volatilities increased when firms paid stock options as executive compensation. They analyzed the relation between stock option compensation and risk taking, by examining whether ESOs provided managers with incentives to invest in risky plans. They found that an ESO's risk incentive is positively correlated with future risk taking. Regarding manager's excessive risk taking, [7] concerned themselves with the question of whether ESOs could induce excessive risk taking by managers in firms' security issue decisions. Their results supported the suggestion that stock options could sometimes make managers take on too much risk.

In short, we consider the increasing stock volatilities discussed by [7] and [16], the resettable feature of ESOs analyzed by [21], the cash dividend payments, and American style exercises with regard to ESO valuation.

\section{A Framework for Valuing Bermudan Reset Executive Stock Options}

This section will derive the exact valuation of Bermudan reset executive stock options with cash dividends. We give some basic assumptions first and then derive the closed-form approximate solutions of the option.

\subsection{Basic Assumption}

Option contract has become a useful financial instrument in hedging, arbitraging, and speculating since [17] derived the closed-form formula of plain vanilla options in 1973. We follow the basic arguments of [17] to construct our analysis of ESOs. That is, the stock price, $S$, follows a geometric Brown motion. The option price, $C$, is a function of the stock price and time, and it satisfies the Black-Scholes partial differential equation (PDE) as follows:

$$
\frac{1}{2} \sigma^{2} S^{2} C_{S S}+r_{f} S C_{S}+C_{t}=r_{f} C,
$$

where $\sigma$ and $r_{f}$ denote the stock's volatility and risk-free interest rate, respectively. $t$ is the time. The current time is taken to be date $t_{0}$; thus the time left to maturity is denoted as $\tau_{0}=T-t_{0}$.

After the following transformation of variables, Equation (1) will be simplified into the homogeneous heat equation as in Equation (3).

$$
\left\{\begin{array}{l}
\tau=T-t \\
x=\ln S+\left(r_{f}-\frac{\sigma^{2}}{2}\right) \tau \\
U(x(S), \tau)=\mathrm{e}^{r_{f} \cdot \tau} C(S, \tau) \\
\frac{\sigma^{2}}{2} U_{x x}=U_{\tau},
\end{array}\right.
$$

where $U$ denotes the transformed price of the option. 
Next, we follow the empirical results of [16] and assume the volatility of the stock price satisfies the predetermined increasing term structure when the firm pays stock options to executives as their compensation.

In a real case, a firm would periodically pay dividends to shareholders, so we consider a pricing model with several cash dividend payments. On the other hand, when discrete-time cash dividends are analyzed in an executive stock option valuation, the American-type mechanism offers more incentives to executives than the European type does. However, the increase of firm value via executive stock option payments is insignificant if the ESO is early-exercised within a short time frame. Therefore, most executive stock option contracts are formed as a Bermudan-type with cash dividends; such Bermudan-type ESOs allow executives to have a lot of exercise rights between the instant after the lock-up period and the expiry date.

Furthermore, a poor performance in stock markets is not always attributed to the executive, so ESOs usually give the executives gains via the reset strike price mechanism. Following [21], we design a resetting mechanism that will resist the worst economic environments and offer executives encouraging compensations. In order to simplify the valuation model, we consider a one period resetting model with a reset date $t_{1}$ and an ex-dividend date $t_{2}\left(t_{1} \leq t_{2}\right)$ later. $^{1}$

\subsection{Initial Value Problem of PDE}

The valuation of Bermudan resetting executive stock options with cash dividends is a sequence of initial value problems of PDE. Given the terminal payoff of options after a variable transformation (2), we obtain the initial condition of the heat equation as follows:

$$
U(x, 0)= \begin{cases}0, & \text { if } \mathrm{e}^{x} \leq K \\ \mathrm{e}^{x}-K, & \text { if } \mathrm{e}^{x}>K\end{cases}
$$

We introduce a fundamental solution for the heat Equation (3)-the Green function with the infinite domain as follows:

$$
G\left(x, \tau ; x_{0}, \tau_{0}\right)=\frac{1}{\sqrt{2 \pi \sigma^{2}\left(\tau_{0}-\tau\right)}} \exp \left[\frac{-\left(x_{0}-x\right)^{2}}{2 \sigma^{2}\left(\tau_{0}-\tau\right)}\right] H\left(\tau_{0}-\tau\right),
$$

where $H\left(\tau_{0}-\tau\right)$ is the Heaviside step function,

$$
H\left(\tau_{0}-\tau\right)= \begin{cases}1, & \text { if } \tau_{0}-\tau \geq 0 \\ 0, & \text { if } \tau_{0}-\tau<0\end{cases}
$$

Based on the previous fundamental function, a closed-form approximate solution after the instant of the ex-dividend date $\tau_{2}$ will be presented as Equation (7) via the integral representation, which is a convolution of the initial condition and the Green function,

$$
U_{2}^{-}\left(x_{2}^{-}, \tau_{2}^{-}\right)=\int_{-\infty}^{\infty} U(x, 0) G\left(x, 0 ; x_{2}^{-}, \tau_{2}^{-}\right) \mathrm{d} x,
$$

${ }^{1}$ In the next section, we use the variable transformation as Equation (2) so that the reset date $t_{1}$ will transform to $\tau_{1}$, and the ex-dividend date $t_{2}$ will be $\tau_{2}$. 
where the transformed stock price after the instant of the ex-dividend date $\tau_{2}$ is $x_{2}^{-}=\ln \left(S_{2}^{+}-d\right)+\left(r_{f}-\frac{\sigma_{2}^{2}}{2}\right) \tau_{2}^{-}$.

The stock volatility from the ex-dividend date to maturity is a constant, $\sigma_{2}$. The cash dividend is denoted as $d$. The stock price before the instant of ex-dividend is $S_{2}^{+}$.

Nevertheless, if the cash dividend $d$ is large enough, the option holders will want to early exercise before the ex-dividend date. Hence, there exists an early exercised threshold value $S_{2}^{*}$, which satisfies the following Equation (8). The economic meaning of threshold value $S_{2}^{*}$ is that if the stock price before the instant of ex-dividend is higher than $S_{2}^{*}$, the ESO will be early exercised as the strike price $K$. Contrarily, if the stock price before the instant of ex-dividend is smaller than $S_{2}^{*}$, the stock with an ESO will be paid dividend.

$$
C_{2}\left(S_{2}^{+}, \tau_{2}^{+}\right)=\left\{\begin{array}{ll}
S_{2}^{+}-K, & \text { if } S_{2}^{+} \geq S_{2}^{*} \\
U_{2}^{-}\left(x_{2}^{-}, \tau_{2}^{-}\right) \cdot \mathrm{e}^{-r_{f} \cdot \tau_{2}^{-}}, & \text {if } S_{2}^{+}<S_{2}^{*}
\end{array},\right.
$$

where $x_{2}^{-}=\ln \left(S_{2}^{+}-d\right)+\left(r_{f}-\frac{\sigma_{2}^{2}}{2}\right) \tau_{2}^{-} ; K$ is the strike price of the option; $S_{2}^{+}$is the stock price before the instant of ex-dividend.

Next, we will determine whether the strike price $K$ of the ESO resets or not at the reset date $\tau_{1}$. This investigation considers two situations, as follows:

Case A: If the stock price is lower than the reset threshold $\alpha E$, the strike price $K$ will be reset as the stock price at the reset date $\tau_{1}$. Case A in Figure 1 presents the case where the option strike price will be reset as the stock price $S_{1}$ at the reset date.

Case B: If the stock price is higher than the reset threshold $\alpha E$, the strike price $K$ will still be the original strike level, $E$. Case B in Figure 1 presents the case where the option strike price is the original exercise level $E$ at the reset date.

This study uses an integral representation to obtain the closed-form approximate solution of the option pricing at the reset date $\tau_{1}$ as follows:

$$
U_{1}\left(x_{1}, \tau_{1}\right)=\int_{-\infty}^{\infty} U_{2}^{+}\left(x_{2}^{+}, \tau_{2}^{+}\right) G\left(x_{2}^{+}, \tau_{2}^{+} ; x_{1}, \tau_{1}\right) \mathrm{d} x_{2}^{+},
$$
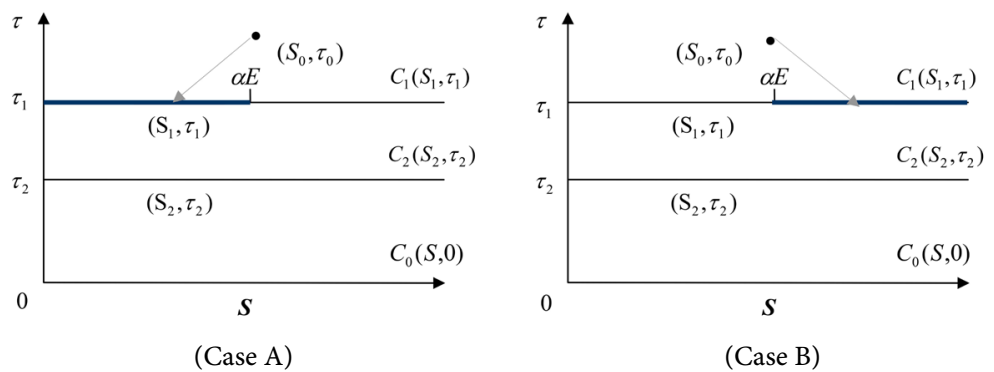

Figure 1. The valuation of Bermudan executive stock options with reset strike price $K$ $=S_{1}$ in Case A and $K=E$ in Case B, respectively. Note: $\alpha$ denotes the reset rate. If $S_{1}$ is lower than $\alpha E$, the strike price of options will be reset as the stock price at reset date $\tau_{1}$. Otherwise, the strike price of options will be the original strike level, $E$. 
where transformed stock prices at the reset date $\tau_{1}$ and the instant before the ex-dividend date $\tau_{2}$ are $x_{1}=\ln \left(S_{1}\right)+\left(r_{f}-\frac{\sigma_{1}^{2}}{2}\right)\left(\tau_{1}-\tau_{2}\right)+\left(r_{f}-\frac{\sigma_{2}^{2}}{2}\right) \tau_{2} \quad$ and $x_{2}^{+}=\ln \left(S_{2}^{+}\right)+\left(r_{f}-\frac{\sigma_{2}^{2}}{2}\right) \tau_{2}^{+}$, respectively. The stock volatility from the reset date to the ex-dividend date is a constant, $\sigma_{1}$. At the instant before the ex-dividend date $\tau_{2}$, the transformed option price is denoted as $U_{2}^{+}\left(x_{2}^{+}, \tau_{2}^{+}\right)$,

$$
U_{2}^{+}\left(x_{2}^{+}, \tau_{2}^{+}\right)= \begin{cases}\left(S_{2}^{+}-K\right) \cdot \mathrm{e}^{r_{f} \cdot \tau_{2}^{+}}, & \text {if } S_{2}^{+} \geq S_{2}^{*} \\ U_{2}^{-}\left(x_{2}^{-}, \tau_{2}^{-}\right), & \text {if } S_{2}^{+}<S_{2}^{*}\end{cases}
$$

where the transformed stock price at the instant after the ex-dividend date $\tau_{2}$ is $x_{2}^{-}=\ln \left(S_{2}^{+}-d\right)+\left(r_{f}-\frac{\sigma_{2}^{2}}{2}\right) \tau_{2}^{-}$.

Finally, we obtain the present option value via the recursive integral technique as follows:

$$
C\left(S_{0}, t_{0}\right)=U\left(x_{0}, \tau_{0}\right) \cdot \mathrm{e}^{-r_{f} \cdot \tau_{0}}=\mathrm{e}^{-r_{f} \cdot \tau_{0}} \cdot \int_{-\infty}^{\infty} U_{1}\left(x_{1}, \tau_{1}\right) G\left(x_{1}, \tau_{1} ; x_{0}, \tau_{0}\right) \mathrm{d} x_{1},
$$

where the stock volatility from the present to the reset date is a constant, $\sigma_{0}$. The transformed present time to maturity is $\tau_{0}=T-t_{0}$. The transformed stock prices at the reset date $\left(\tau_{1}\right)$ and the present time to maturity $\left(\tau_{0}\right)$ are $x_{1}$ and $x_{0}$, respectively, which are as follows:

$$
\begin{gathered}
x_{1}=\ln \left(S_{1}\right)+\left(r_{f}-\frac{\sigma_{1}^{2}}{2}\right)\left(\tau_{1}-\tau_{2}\right)+\left(r_{f}-\frac{\sigma_{2}^{2}}{2}\right) \tau_{2} \\
x_{0}=\ln \left(S_{0}\right)+\left(r_{f}-\frac{\sigma_{0}^{2}}{2}\right)\left(\tau_{0}-\tau_{1}\right)+\left(r_{f}-\frac{\sigma_{1}^{2}}{2}\right)\left(\tau_{1}-\tau_{2}\right)+\left(r_{f}-\frac{\sigma_{2}^{2}}{2}\right) \tau_{2}
\end{gathered}
$$

\section{Numerical Example}

This section discusses the effect of the impact factors on the ESOs' valuations with a simple numerical example, for a clear understanding of the ESO price changes. The study assumes that the reset date equals the ex-dividend date, that is $t_{1}=t_{2}$. In addition, the reset strike price $K$ is equal to $S_{1}^{+}$when the stock price at the instant before $\tau_{1}$ satisfies the condition $S_{1}^{+}-d<\alpha E$. Otherwise, the strike price is equal to the original level, $E$.

\subsection{Effect of Cash Dividends on Option Prices at the Ex-Dividend Date}

Since the cash dividend is a critical factor related to early exercise in executive stock options, we first analyze the effect of cash dividends on option prices. Figure 2 shows the option prices with cash dividends of $\$ 0$ and $\$ 20$ across stock prices at the ex-dividend date as reset rate 0 , respectively. Most importantly, when the cash dividend is equal to $\$ 0$, the option valuation at the ex-dividend date is analogous to that of a vanilla option. When the cash dividend is equal to 
\$20, an American-type executive stock option will be early exercised at the ex-dividend date as long as the stock price is higher than the critical value \$101.8666 shown in Figure 2.

\subsection{Evaluations of Options with Cash Dividends and Reset Rates}

We discuss the valuation of options with a cash dividend of $\$ 20$ and reset rate 0.6 in this example. Figure 3 shows the values of both the vanilla and executive stock options with a cash dividend of $\$ 20$ and a reset rate of 0.6 under various current stock prices. The value of the ESO with the cash dividend of $\$ 20$ and reset rate of 0.6 is always lower than the value of the vanilla option in Figure 3. Equation (14) shows that the limit difference is $\$ 3.6927$ when the current stock price is large enough.

$$
3.9211 \times \mathrm{e}^{-r_{f} \cdot\left(\tau_{0}-\tau_{1}\right)}=3.9211 \times \mathrm{e}^{-0.1 \cdot(1-0.4)}=3.6927
$$

\subsection{Sensitive Analysis}

This section undertakes a sensitivity analysis of all factors. The fundamental setting for the related parameters is as follows: the present stock price $S_{0}=\$ 100$; the exercise price $E=\$ 100$; the current time to maturity $\tau_{0}=1$ (year); the ex-dividend date to maturity is equal to the reset date to maturity, $\tau_{1}=\tau_{2}=0.4$ (year); the volatility of stock price between the ex-dividend date to maturity and current time to maturity $\left[\tau_{1}, \tau_{0}\right], \sigma_{0}=0.25$; the volatility of stock price between the maturity and ex-dividend date to maturity $\left[0, \tau_{1}\right], \sigma_{1}=0.3$; the risk-free rate $r_{f}=0.1$; the reset rate $\alpha=0.6$, and the cash dividend $d=\$ 20$.

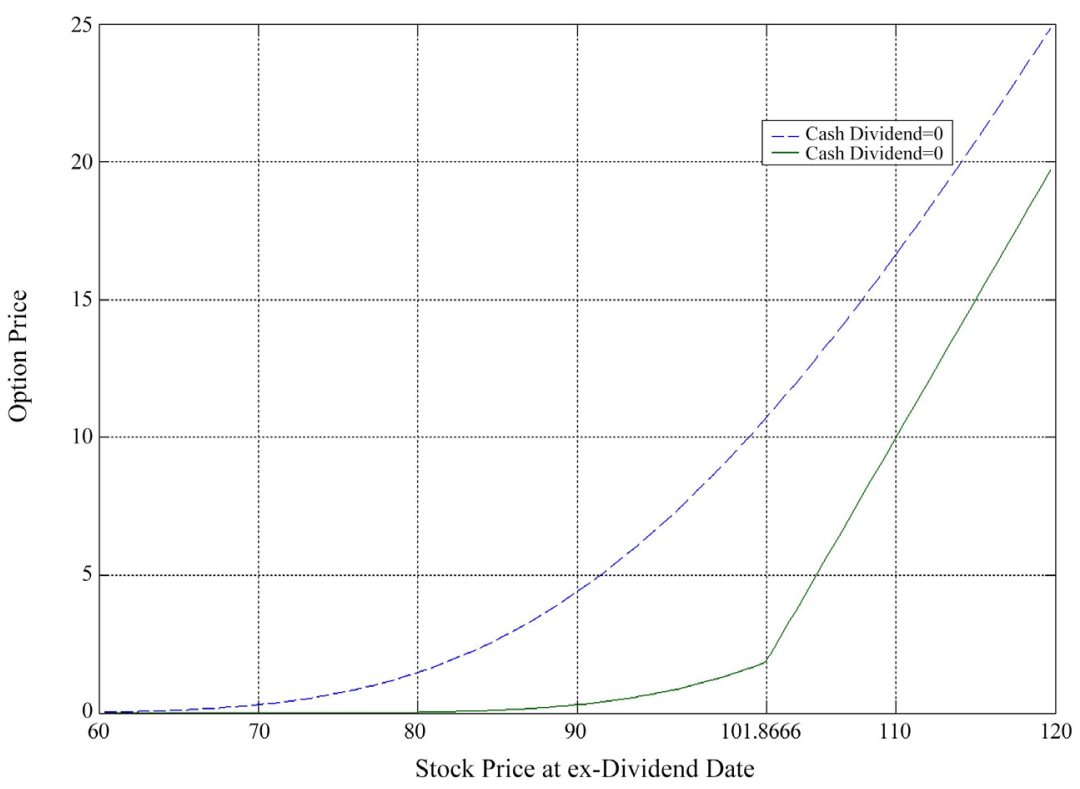

Figure 2. The option prices with cash dividends of $\$ 0$ and $\$ 20$, respectively, as the reset rate 0 under various stock prices at the ex-dividend date. Note: The current time to maturity $\tau_{0}=1$. The ex-dividend date to maturity is equal to the reset date to maturity, $\tau_{1}=\tau_{2}=0.4$. The volatilities of stock prices are $\sigma_{0}=\sigma_{1}=0.3$. The risk-free rate is $r_{f}=0.1$. The exercise price is $E=\$ 100$. The reset rate is $\alpha=0$. 


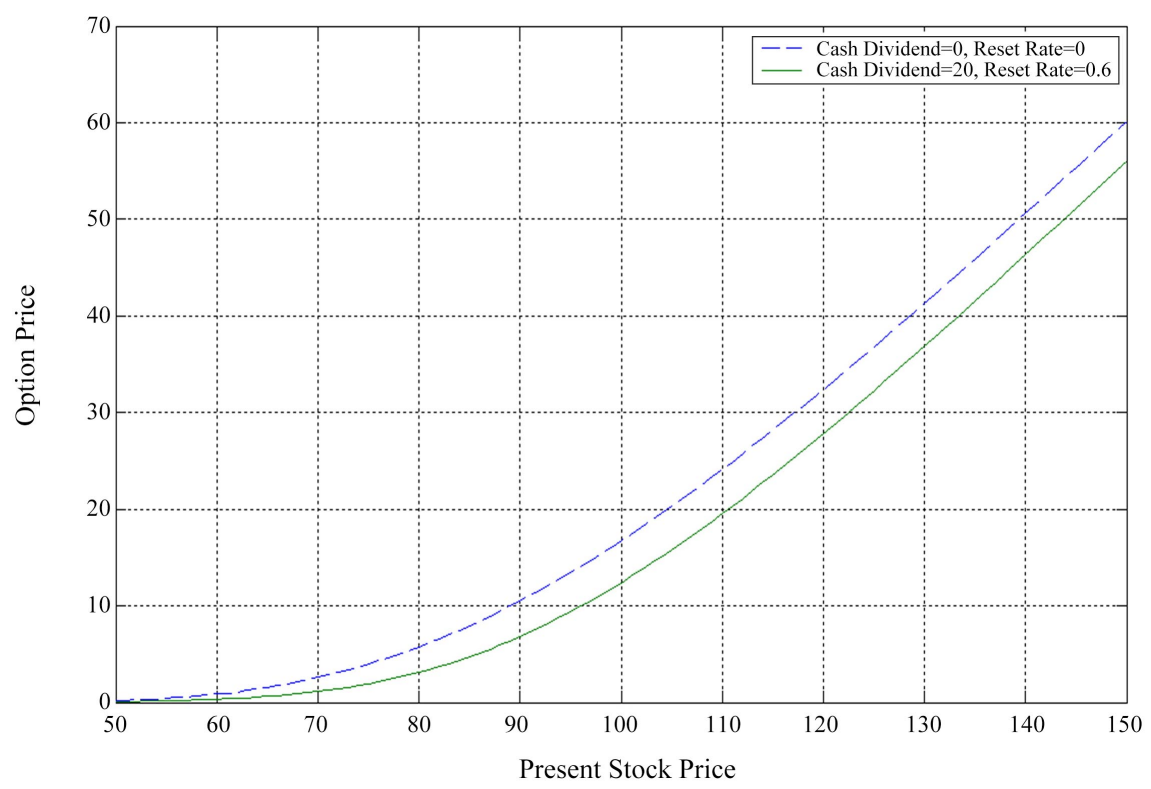

Figure 3. The option values with a cash dividend of $\$ 20$ and a reset rate of 0.6 , and the vanilla option, respectively. Note: We assume that the current time to maturity, $\tau_{0}=1$. The ex-dividend date to maturity is equal to the reset date to maturity, $\tau_{1}=\tau_{2}=0.4$. The volatilities of stock price are $\sigma_{0}=\sigma_{1}=0.3$. The risk-free rate is $r_{f}=0.1$, and the exercise price is $E=\$ 100$.

1) The Effect of Stock price

Disclosing the option values under various stock prices in Table 1, the option values are positively correlated to the stock prices. In Table 1, the margin effect of stock prices on option values is almost consistent when the current stock price is high. That is, the time value approaches zero when the option contract stays deep in-the-money. Figure 4 displays the tendency of the delta, which is the hedging ratio of option to stock. The results in Table 1 and Figure 4 are consistent.

2) The Effect of Volatilities of Stock price

Plots of Case A and Case B in Figure 5 show the marginal effects of stock price volatility $\sigma_{0}$ on the option prices in $\left[\tau_{1}, \tau_{0}\right]$ and $\sigma_{1}$ in $\left[0, \tau_{1}\right]$, respectively. We see that the effect of $\sigma_{0}$ in $\left[\tau_{1}, \tau_{0}\right]$ is more significant than $\sigma_{1}$ in $\left[0, \tau_{1}\right]$. This difference is attributed to the large probability of early exercise with large volatility $\sigma_{0}$. Moreover, there is a positive relation between option values and stock price volatilities in Figure 5.

3) The Effect of Exercise Price

The exercise price is the cost to obtain the underlying asset, so the option values will decrease while the exercise prices increase. Figure 6 shows the option values under various exercise prices, and we see that there exists a significantly negative and near straight-line relationship between the option values and exercise prices.

4) The Effect of Risk-Free Rate 
The present value of the cost of obtaining the underlying asset in the future is low when the risk-free rate is high. As a result, the option values are positively correlated with the risk-free rate. Figure 7 shows the option values under various risk-free rates. There is a significantly positive and near straight-line relationship between the option values and the risk-free rates. This is directly opposite to the effect of the exercise prices on option values.

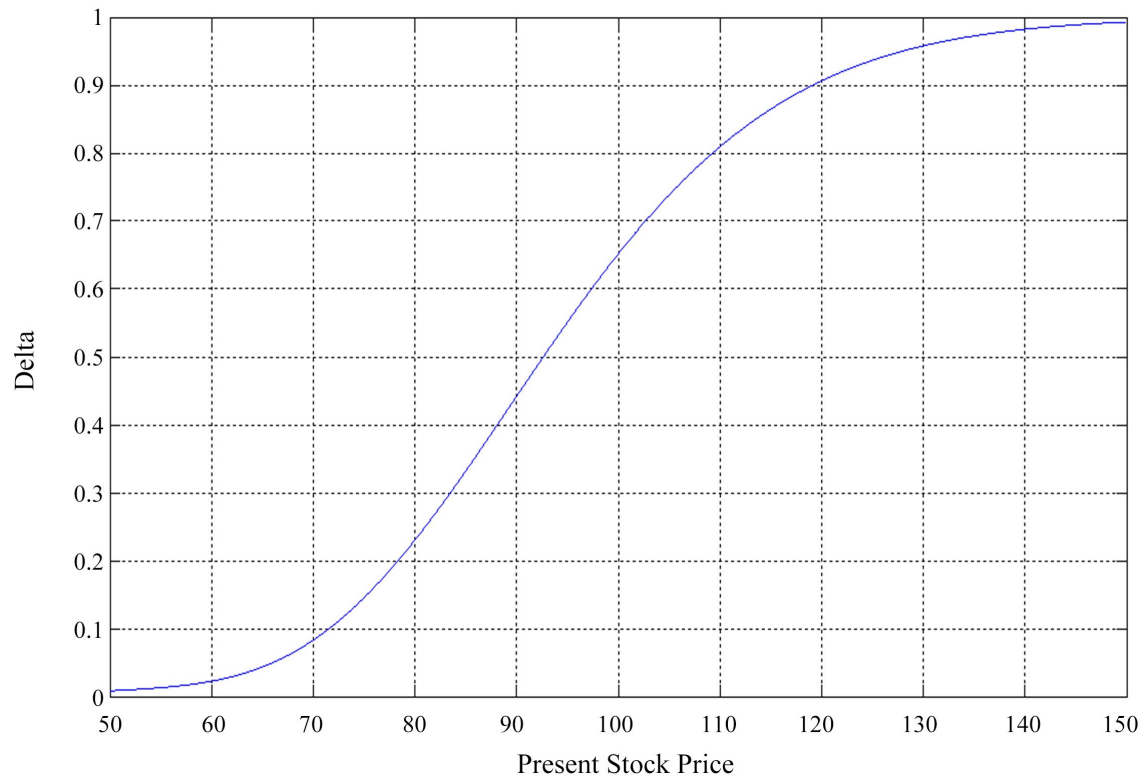

Figure 4. The hedging ratio of option to stock under various current stock prices when we consider the term-structure of increasing stock volatilities, the reset rate, and the cash dividend. Note: We assume that the current time to maturity $\tau_{0}=1$; the ex-dividend date to maturity is equal to the reset date to maturity, $\tau_{1}=\tau_{2}=0.4$; the volatilities of stock prices, $\sigma_{0}=0.25, \sigma_{1}=0.3$; the risk-free rate $r_{f}=0.1$; the exercise price $E=\$ 100$; the reset rate $\alpha=0.6$, and the cash dividend $d=\$ 20$.

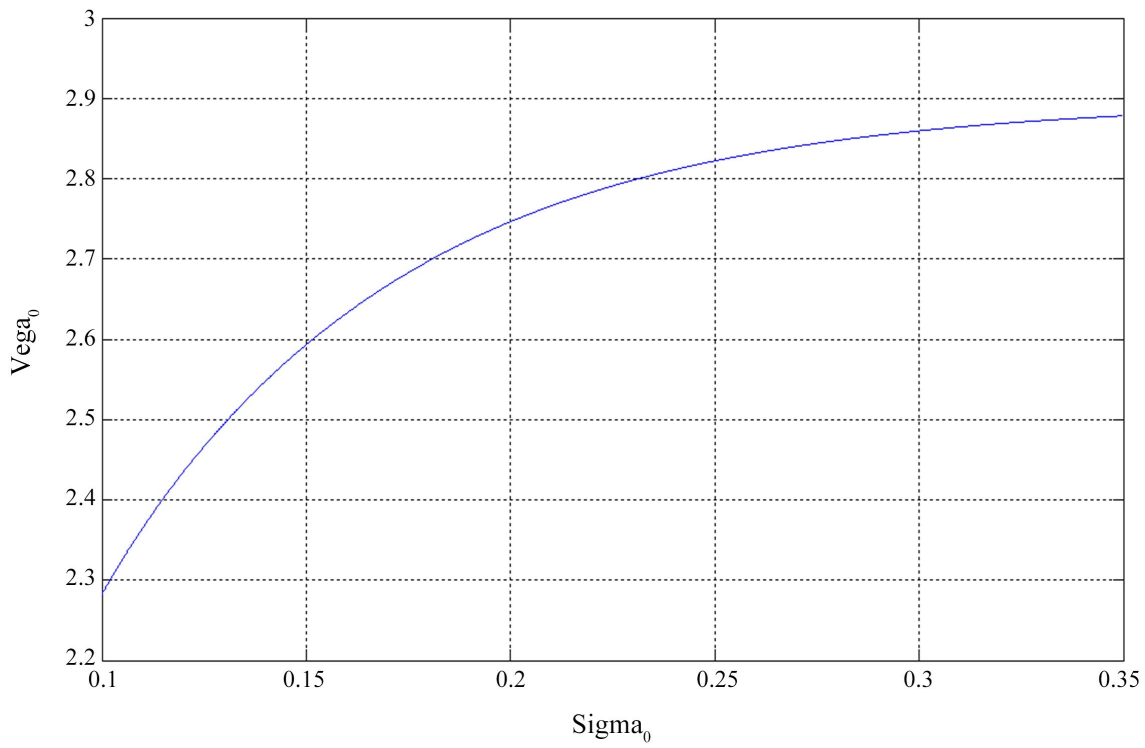

(Case A) 


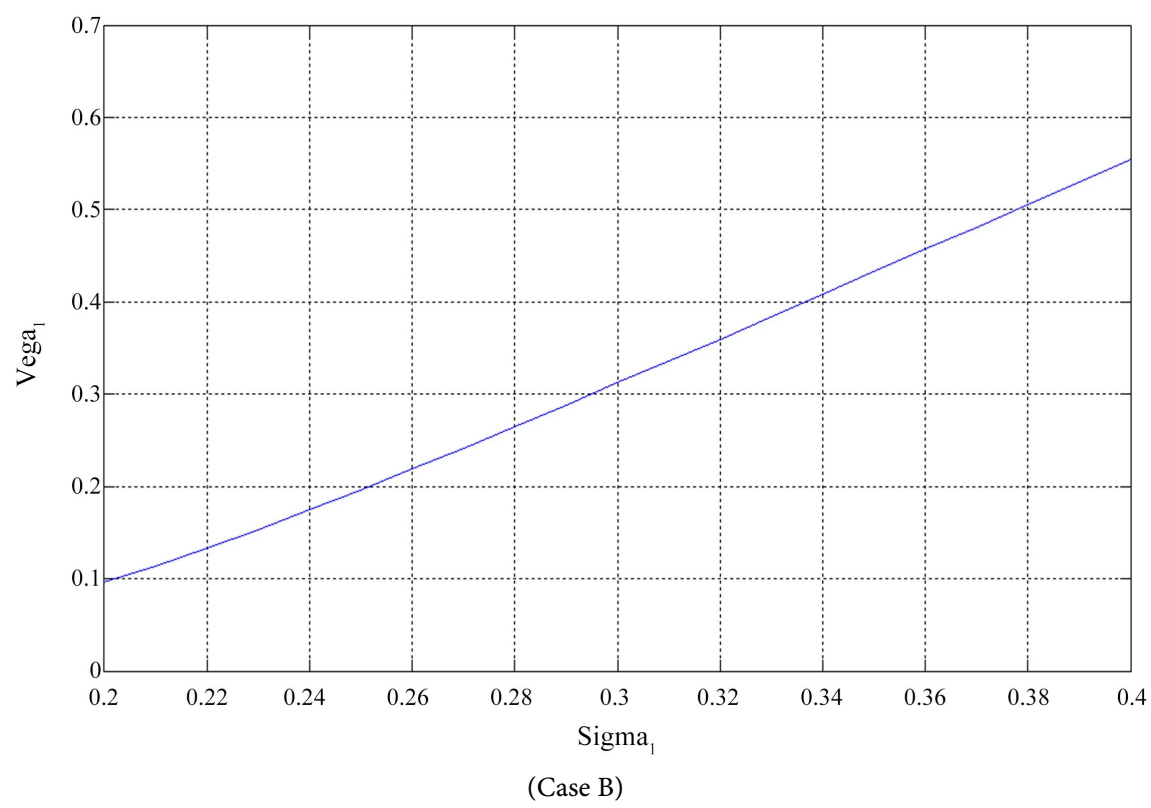

Figure 5. The marginal effects of stock volatilities on option prices. Case A. The marginal effects of option price for $0.1 \%$ increment of stock volatility $\sigma_{0}$ in $\left[\tau_{1}, \tau_{0}\right]$ when we fix $\sigma_{1}=0.3$ in $\left[0, \tau_{1}\right]$. Case B. The marginal effects of option prices for $0.1 \%$ increments of stock volatility $\sigma_{1}$ in $\left[0, \tau_{1}\right]$ when we fix $\sigma_{0}=0.25$ in $\left[\tau_{1}, \tau_{0}\right]$. Note: The current stock price $S_{0}=\$ 100$; the exercise price $E=\$ 100$; the current time to maturity $\tau_{0}=1$; the ex-dividend date to maturity is equal to the reset date to maturity, $\tau_{1}=\tau_{2}=0.4$; the risk-free rate $r_{f}=0.1$; the reset rate $\alpha=0.6$, and the cash dividend $d=\$ 20$.

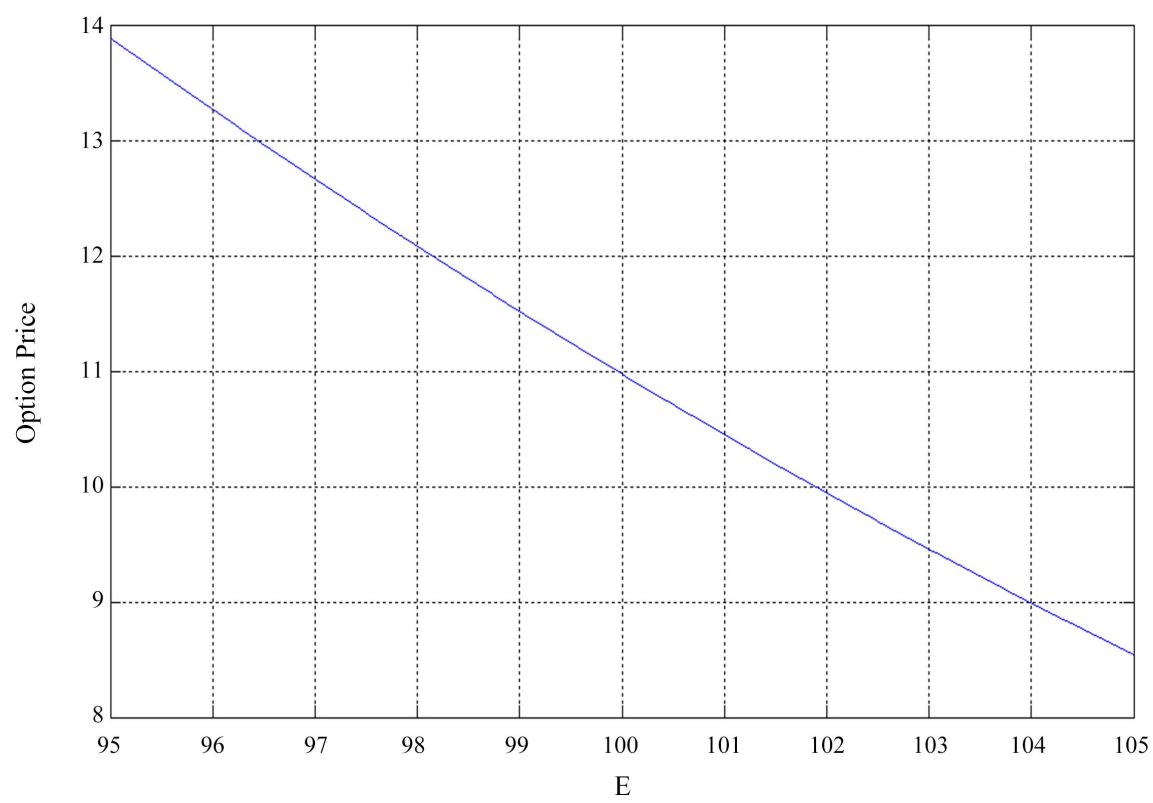

Figure 6. The option values under various exercise prices. Note: The current stock price $S_{0}=\$ 100$; the current time to maturity $\tau_{0}=1$; the ex-dividend date to maturity is equal to the reset date to maturity, $\tau_{1}=\tau_{2}=0.4$; the volatilities of stock prices, $\sigma_{0}=0.25$, $\sigma_{1}=0.3$; the risk-free rate $r_{f}=0.1$; the reset rate $\alpha=0.6$, and the cash dividend $d=$ $\$ 20$. 


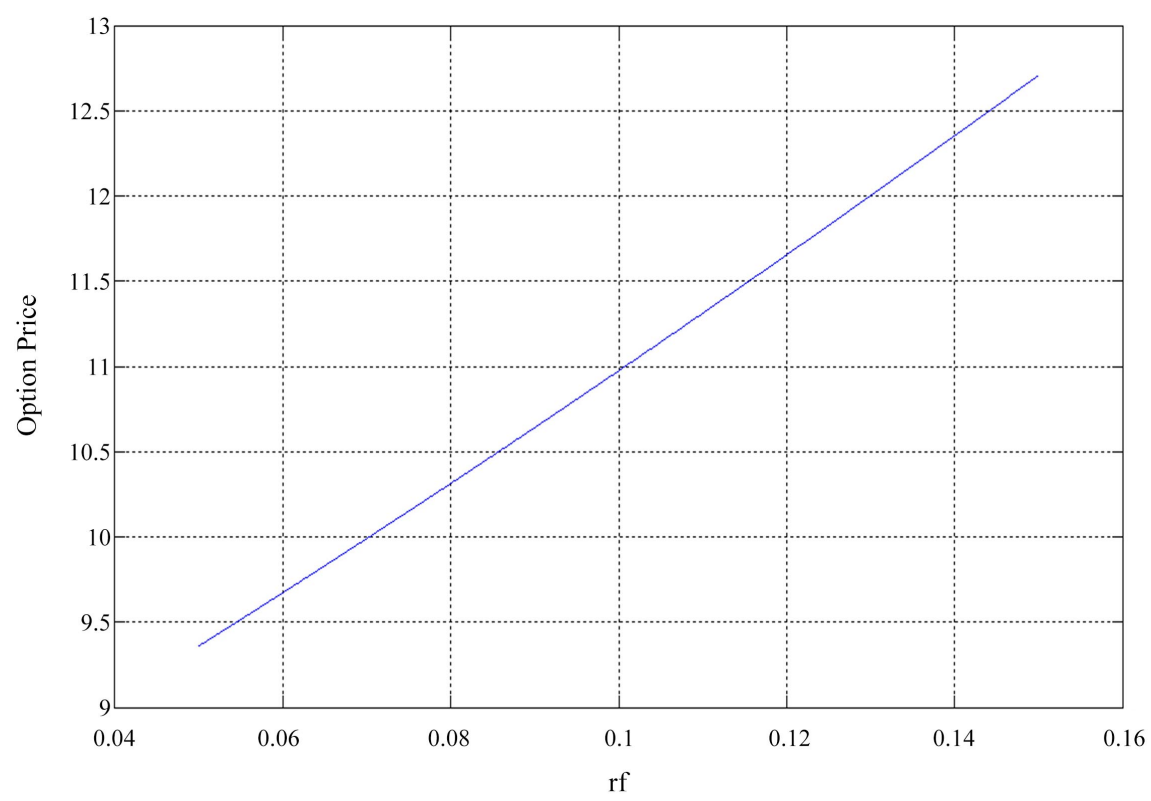

Figure 7. The option values under various risk-free rates. Note: The current stock price $S_{0}$ $=\$ 100$; the exercise price $E=\$ 100$; the current time to maturity $\tau_{0}=1$; the ex-dividend date to maturity is equal to the reset date to maturity, $\tau_{1}=\tau_{2}=0.4$; the volatilities of stock prices, $\sigma_{0}=0.25, \sigma_{1}=0.3$; the reset rate $\alpha=0.6$, and the cash dividend $d=\$ 20$.

Table 1. Option values under different current stock prices.

\begin{tabular}{cc}
\hline Current Stock Price & Option Value \\
\hline 60 & 0.2019 \\
80 & 2.1518 \\
100 & 10.9741 \\
120 & 26.9449 \\
140 & 46.0105 \\
160 & 65.8497 \\
180 & 85.8268 \\
200 & 105.8239 \\
220 & 125.8235 \\
240 & 145.8235 \\
\hline
\end{tabular}

Note: Assume that the exercise price $E=\$ 100$; the current time to maturity $\tau_{0}=1$; the ex-dividend date to maturity is equal to the reset date to maturity, $\tau_{1}=\tau_{2}=0.4$; the volatility of stock price between $\left[\tau_{1}, \tau_{0}\right]$, $\sigma_{0}=0.25$; the volatility of stock price between $\left[0, \tau_{1}\right], \sigma_{1}=0.3$; the risk-free rate $r_{f}=0.1$; the reset rate $\alpha=0.6$, and the cash dividend $d=\$ 20$.

\section{5) The Effect of Reset Rate}

Increasing the reset rate is beneficial for option holders. As a result, there is a positive relation between the option values and reset rates. Table 2 sets out the option values under various reset rates. We find that the marginal option value is 
nearly constant when the reset rate is below a certain level because a reset rate which is too low cannot increase the option value to any significant degree.

6) The Effect of Cash Dividend

Paying cash dividends to shareholders not only reduces the problem of excess cash flow in firms, but also directly mitigates the agency problem between managers and shareholders. Moreover, an option's value will decrease, since paying cash dividends will cause the stock price to decrease. Therefore, a higher cash dividend will increase the probability of the early exercise of American-type options. Figure 8 shows the critical values of early exercise under various cash dividends at the ex-dividend date. In this example, when the cash dividend is lower than \$3.9211, the critical threshold of early exercise approaches infinity. That is, the options are never early exercised before maturity as long as the cash dividend is lower than $\$ 3.9211$, in this case. Otherwise, when the cash dividend is large enough, the critical threshold of early exercise will reduce to the strike price of $\$ 100$. This means that an option with a large cash dividend is almost surely to be early exercised when the stock price is higher than the strike price of $\$ 100$ at the ex-dividend date.

Table 3 details two scenarios of stock volatilities affecting the prices of the option, with reset rates 0 and 0.6 , respectively, under various cash dividends. This study shows that the option value decreases when the cash dividend increases, a situation which appears in both scenarios A and B of Table 3. At the same time, we see that the impact of the cash dividend on option value is greater than the impact of the reset rate, regardless of the scenarios. There is a positive relation between option values and reset rates, whereas the relation between option values and cash dividends is opposite.

Table 2. The option values under different reset rates.

\begin{tabular}{cc}
\hline Reset Rate & Option Value \\
\hline 0.80 & 11.1372 \\
0.75 & 11.1116 \\
0.70 & 11.0592 \\
0.65 & 11.0090 \\
0.60 & 10.9741 \\
0.55 & 10.9552 \\
0.50 & 10.9470 \\
0.45 & 10.9443 \\
0.40 & 10.9436 \\
\hline
\end{tabular}

Note: The stock price $S_{0}=\$ 100$; the exercise price $E=\$ 100$; the time to maturity $\tau_{0}=1$; the ex-dividend date to maturity is equal to the reset date to maturity, $\tau_{1}=\tau_{2}=0.4$; the volatility of stock price between $\left[\tau_{1}, \tau_{0}\right], \quad \sigma_{0}=0.25$; the volatility of stock price between $\left[0, \tau_{1}\right], \sigma_{1}=0.3$; the risk-free rate $r_{f}=0.1$, and the cash dividend $d=\$ 20$. 
Table 3. The option values under different cash dividends.

\begin{tabular}{ccccc}
\hline \multirow{2}{*}{$\begin{array}{c}\text { Cash } \\
\text { Dividend }\end{array}$} & \multicolumn{2}{c}{$\sigma_{0}=\sigma_{1}=0.3$} & \multicolumn{2}{c}{ Scenario B } \\
\cline { 2 - 5 } & Reset Rate $\alpha=0$ & Reset Rate $\alpha=0.6$ & Reset Rate $\alpha=0$ & Reset Rate $\alpha=0.6$ \\
\hline 0 & 16.7341 & 16.7349 & 15.7136 & 15.7138 \\
4 & 14.5036 & 14.5050 & 13.4003 & 13.4008 \\
8 & 13.3453 & 13.3478 & 12.0794 & 12.0805 \\
12 & 12.8034 & 12.8074 & 11.4570 & 11.4591 \\
16 & 12.5124 & 12.5185 & 11.1249 & 11.1285 \\
20 & 12.3530 & 12.3630 & 10.9437 & 10.9493 \\
\hline
\end{tabular}

Note: The stock price $S_{0}=\$ 100$; the exercise price $E=\$ 100$; the current time to maturity $\tau_{0}=1$; the ex-dividend date to maturity is equal to the reset date to maturity, $\tau_{1}=\tau_{2}=0.4$, and the risk-free rate $r_{f}=0.1$. In Scenario A, the volatilities of stock prices between $\left[\tau_{1}, \tau_{0}\right]$ and $\left[0, \tau_{1}\right]$ are $\sigma_{0}=0.3$ and $\sigma_{1}=0.3$, respectively. In Scenario B, the volatilities of stock prices between $\left[\tau_{1}, \tau_{0}\right]$ and $\left[0, \tau_{1}\right]$ are $\sigma_{0}=0.25$ and $\sigma_{1}=0.3$, respectively.

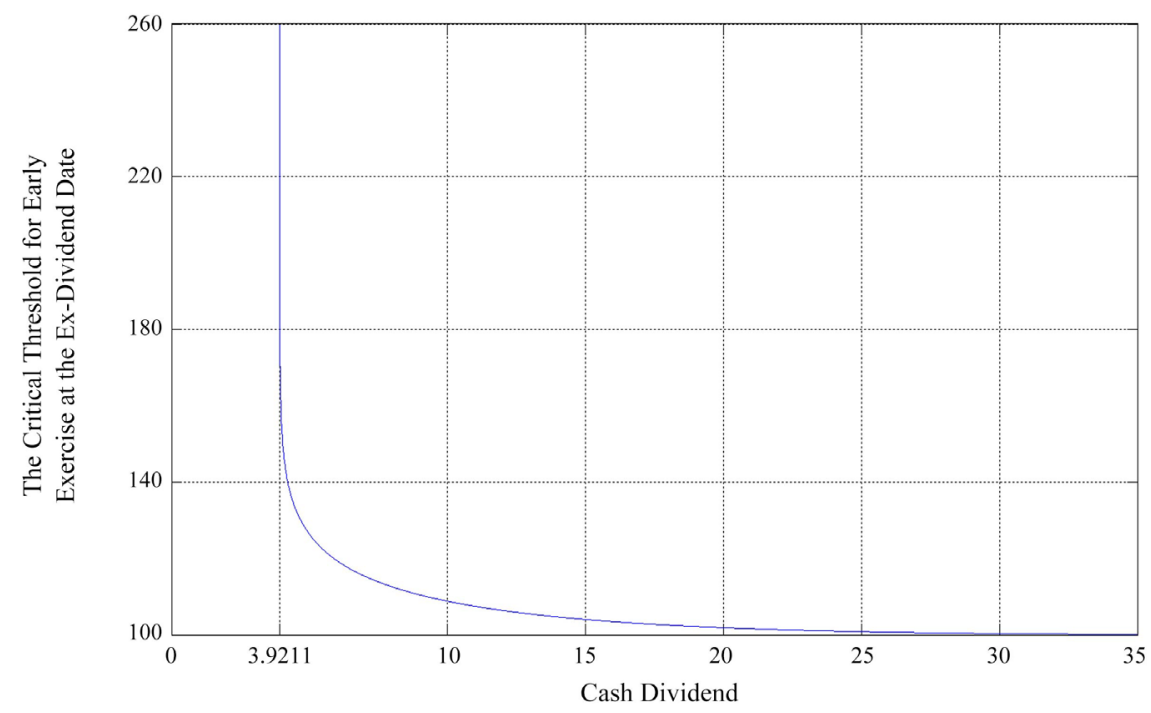

Figure 8. The critical thresholds for early exercise under various cash dividends at the ex-dividend date. Note: The current stock price $S_{0}=\$ 100$; the exercise price $E=\$ 100$; the current time to maturity $\tau_{0}=1$; the ex-dividend date to maturity is equal to the reset date to maturity $\tau_{1}=\tau_{2}=0.4$; the volatilities of stock price $\sigma_{0}=\sigma_{1}=0.3$, and the risk-free rate $r_{f}=0.1$.

\section{Conclusions}

The objective of this investigation is to derive a closed-form approximate solution of Bermudan reset executive stock options with cash dividends via an integral representation method, which is a convolution of a sequence of initial conditions and Green's function. We extend the concept of a reset mechanism studied by [21] and consider the increasing volatilities characteristic studied by [16] to derive the valuation with increasing term-structures of stock volatility. Based on the fundamental assumptions and the recursive integral technique, this 
study has successfully derived the closed-form approximate solutions of Bermudan reset ESOs which embody several complex stylistic features.

This study conducts some numerical examples to discuss the effects of cash dividends, reset rate, and other option parameters on the option values. Specifically, when the current stock price is high enough, the limit of the differences between option values with cash dividends of $\$ 0$ and $\$ 20$, respectively, is $\$ 3.9211$, regardless of the reset rate. The difference between option values with cash dividends of $\$ 0$ and $\$ 20$, respectively, reaches its maximum when the current stock price is at the early exercise threshold, $\$ 101.8666$. Moreover, the present stock price is too high for early exercise of an American option with a cash dividend of $\$ 20$ at the ex-dividend date, so the difference between the options with cash dividends $\$ 0$ and $\$ 20$ will be the discount of $\$ 3.9211$, which is $\$ 3.6927$. Thus, ESO holders have several optimal exercise strategies in certain scenarios to maximize benefits. Specifically, the holders should take cash dividends and reset conditions into account when deciding whether or not to exercise.

In addition, we summarize some interesting results about option values and hedge ratios via the numerical examples. The present stock price, volatility of stock price, reset rate, and risk-free rate all have a positive relation to the option value. The strike price and cash dividend have a negative relation to the option value. Furthermore, the effect of the volatility of stock price between the present time to maturity and the ex-dividend date to maturity, $\left[\tau_{1}, \tau_{0}\right]$, is more significant to the volatility between the ex-dividend date to maturity and maturity date, $\left[0, \tau_{1}\right]$.

The findings indicate that our analysis enables a better understanding for valuations and hedging of Bermudan reset executive stock options with cash dividends as compared to those previous studies that separately considered stylized features of ESOs. The results of this study may be interesting to financial decision makers in the fields of corporate finance, risk management, and investment.

\section{Conflicts of Interest}

The authors declare no conflicts of interest regarding the publication of this paper.

\section{References}

[1] Rubinstein, M. (1994) On the Accounting Valuation of Employee Stock Options. Journal of Derivatives, 3, 8-24. https://doi.org/10.3905/jod.1995.407933

[2] Yermack, D. (1995) Do Corporations Award CEO Stock Options Effectively? Journal of Financial Economics, 39, 237-269. https://doi.org/10.1016/0304-405X(95)00829-4

[3] Brenner, M., Sundaram, R.K. and Yermack, D. (2000) Altering the Terms of Executive Stock Options. Journal of Financial Economics, 57, 103-128. https://doi.org/10.1016/S0304-405X(00)00052-0

[4] Hall, B.J. and Murphy, K.J. (2000) Optimal Exercise Prices for Executive Stock Op- 
tions. American Economic Review, 90, 209-214.

https://doi.org/10.1257/aer.90.2.209

[5] Hall, B.J. and Murphy, K.J. (2002) Stock Options for Underdiversified Executives. Journal of Accounting and Economics, 33, 3-42. https://doi.org/10.1016/S0165-4101(01)00050-7

[6] Sircar, R. and Xiong, W. (2007) A General Framework for Evaluating Executive Stock Options. Journal of Economic Dynamics and Control, 31, 2317-2349. https://doi.org/10.1016/j.jedc.2006.07.004

[7] Dong, Z., Wang, C. and Xie, F. (2010) Do Executive Stock Options Induce Excessive Risk Taking? Journal of Banking and Finance, 34, 2518-2529. https://doi.org/10.1016/j.jbankfin.2010.04.010

[8] Huddart, S. (1994) Employee Stock Options. Journal of Accounting and Economics, 18, 207-231. https://doi.org/10.1016/0165-4101(94)00363-7

[9] Kulatilaka, N. and Marcus, A. (1994) Valuing Employee Stock Options. Financial Analysts Journal, 50, 46-56. https://doi.org/10.2469/faj.v50.n6.46

[10] Detemple, J. and Sundaresan, J. (1999) Non-Traded Asset Valuation with Portfolio Constraints: A Binomial Approach. Review of Financial Studies, 12, 835-872. https://doi.org/10.1093/rfs/12.4.835

[11] Rogers, L.C.G. and Scheinkman, J. (2007) Optimal Exercise of Executive Stock Options. Finance and Stochastic, 11, 357-372. https://doi.org/10.1007/s00780-007-0041-9

[12] Carpenter, J. (1998) The Exercise and Valuation of Executive Stock Options. Journal of Financial Economics, 48, 127-158.

[13] Hull, J. and White, A. (2004) How to Value Employee Stock Options. Financial Analysts Journal, 60, 114-119. https://doi.org/10.2469/faj.v60.n1.2596

[14] Acharya, V., John, K. and Sundaram, R. (2000) On the Optimality of Resetting Executive Stock Options. Journal of Financial Economics, 57, 65-101. https://doi.org/10.1016/S0304-405X(00)00051-9

[15] Dybvig, P. and Loewenstein, M. (2003) Employee Reload Options: Pricing, Hedging, and Optimal Exercise. Review of Financial Studies, 16, 145-171. https://doi.org/10.1093/rfs/16.1.0145

[16] Rajgopal, S. and Shevlin, T. (2002) Empirical Evidence on the Relation between Stock Option Compensation and Risk Taking. Journal of Accounting and Economics, 33, 145-171. https://doi.org/10.1016/S0165-4101(02)00042-3

[17] Black, F. and Scholes, M. (1973) The Pricing of Options and Corporate Liabilities. The Journal of Political Economy, 81, 637-654. https://doi.org/10.1086/260062

[18] Gray, S. and Whaley, R. (1997) Valuing S\&P 500 Bear Market Reset Warrants with a Periodic Reset. Journal of Derivatives, 5, 99-106. https://doi.org/10.3905/jod.1997.407987

[19] Gray, S. and Whaley, R. (1999) Reset Put Options: Valuation, Risk Characteristics, and an Application. Australian Journal of Management, 24, 1-20. https://doi.org/10.1177/031289629902400101

[20] Cheng, W. and Zhang, S. (2000) The Analytics of Reset Options. Journal of Derivatives, 8, 59-71. https://doi.org/10.3905/jod.2000.319114

[21] Liao S.L. and Wang, C.W. (2003) The Valuation of Reset Options with Multiple Strike Resets and Reset Dates. The Journal of Futures Markets, 23, 87-107. https://doi.org/10.1002/fut.10055 
[22] Leung, T. and Zhou, Y. (2020) A Top-Down Approach for the Multiple Exercises and Valuation of Employee Stock Options. International Journal of Theoretical and Applied Finance, 23, 1-29. https://doi.org/10.1142/S0219024920500041

[23] Wang, X.C., Su, Z.W. and Xu, G.L. (2018) The Valuation of Executive Stock Options under Garch Models. Probability in the Engineering and Informational Sciences, 32, 409-433. https://doi.org/10.1017/S0269964817000316

[24] Wang, X.C. (2018) Valuing Executive Stock Options under Correlated Employment Shocks. Finance Research Letters, 27, 38-45. https://doi.org/10.1016/j.frl.2018.02.028

[25] Klein, D. (2018) Executive Turnover and the Valuation of Stock Options. Journal of Corporate Finance, 48, 76-93. https://doi.org/10.1016/j.jcorpfin.2017.09.025

[26] Konstandatos, O. (2020) Fair-Value Analytical Valuation of Reset Executive Stock Options Consistent with IFRS9 Requirements. Annals of Actuarial Science, 14, 188-218. https://doi.org/10.1017/S1748499519000125 